\title{
Phenolic acid concentrations in plasma and urine from men consuming green or black tea and potential chemopreventive properties for colon cancer
}

\author{
Susanne M. Henning ${ }^{1,{ }^{*}}$, Piwen Wang ${ }^{1,2}$, Narine Abgaryan ${ }^{1}$, Roberto Vicinanza ${ }^{1}$, Daniela \\ Moura de Oliveira $^{3}$, Yanjun Zhang ${ }^{1}$, Ru-Po Lee ${ }^{1}$, Catherine L. Carpenter ${ }^{1}$, William J. \\ Aronson $^{4}$, and David Heber ${ }^{1}$ \\ ${ }^{1}$ Center for Human Nutrition; David Geffen School of Medicine, University of California, Los \\ Angeles, CA, USA \\ ${ }^{2}$ Division of Cancer Research and Training, Charles R. Drew University of Medicine and Science, \\ Los Angeles, CA, USA \\ ${ }^{3}$ Nutrition Department, School of Public Health, University of São Paulo, São Paulo, Brazil \\ ${ }^{4}$ Department of Urology, David Geffen School of Medicine, University of California, Los Angeles, \\ CA, USA
}

\begin{abstract}
Scope-Tea polyphenols are metabolized by the colonic microflora yielding phenolic metabolites, which may contribute to the health benefits of tea. We determined the serum and urine concentrations of phenolic acids, hippuric acid and polyhydroxyphenyl- $\gamma$-valerolactones during green tea (GT) and black tea (BT) administration. The effects of (-)-epigallocatechin gallate (EGCG) and 3,4-dihydroxyphenylacetic acid (3,4-DHPAA) alone and in combination on bioavailability, intracellular metabolism, and antiproliferative activity was determined in HCT-116 colon cancer cells.

Methods and Results-The concentration of phenolic metabolites was quantified by HPLC with electrochemical detection and MS. Urine concentrations of 4-hydroxyphenylacetic acid (4HPAA), 3-hydroxyphenylacetic acid (3-HPAA) and polyhydroxy- $\gamma$-valerolactones were increased significantly in men drinking GT compared to control. Urine concentration of 3-O-methylgallic acid (3OMGA) was significantly increased in men drinking BT compared to control. Serum 3,4DHPAA was significantly increased after consumption of GT and BT and 4-HPAA after GT consumption. In vitro treatment of HCT-116 colon cancer cells with 3,4-DHPAA and EGCG exhibited an additive antiproliferative effect, while methylation of 3,4-DHPAA was significantly decreased. 3OMGA exhibited the strongest antiproliferative activity among the phenolic acids.
\end{abstract}

Conclusions-The consumption of both, GT and BT, was associated with a significant increase in urinary and serum phenolic acids.

\section{Keywords}

Black tea; EGCG; Green tea; HCT116 colon cancer cells; Phenolic metabolites

\footnotetext{
"For reprints and all correspondence: Professor Susanne M. Henning, Center for Human Nutrition, 900 Veteran Ave, Los Angeles, CA 90095, USA, Tel: (310) 825-9345; Fax: (310) 206-5264; shenning@ mednet.ucla.edu.

CONFLICT OF INTEREST STATEMENT

None of the authors had a conflict of interest.
} 


\section{INTRODUCTION}

A variety of teas including white, green, oolong, black and pu-erh teas are produced from the same plant Camellia sinensis using different post-harvesting methods. For the production of green tea (GT), the leaves are heat-treated to inactivate oxidative enzymes thus retaining a typical GT polyphenol profile. Green tea polyphenols (GTPs), also known as flavan-3-ols, include (-)-epigallocatechin (EGC), (-)-epigallocatechin-3-gallate (EGCG), (-)-epicatechin (EC), and (-)-epicatechin-3-gallate (ECG) [1]. For the production of black tea (BT), the leaves undergo fermentation in moist and warm conditions [1]. Endogenous enzymes enhance the formation of polymers such as theaflavin (THE) and thearubigin. Therefore, BT contains less monomeric polyphenols (3-10\% of solids) and higher concentrations of polymeric polyphenols (23-25\% of solids) compared to GT [1]. In addition a higher concentration of gallic acid is found in BT [2]. The chemical composition of thearubigins is under investigation [3].

Monomeric GTPs are absorbed in the small intestine while polymers such as theaflavin are only marginally absorbed even after the administration of large amounts equivalent to 30 cups of BT [4]. The monomeric and polymeric GTPs remaining in the intestine are transported to the colon and are transformed to $5-\left(3^{\prime}, 4^{\prime} 5^{\prime}\right.$-trihydroxyphenyl $)-\gamma-$ valerolactone (M4), 5-( $3^{\prime}, 4^{\prime}$-dihydroxy)- $\gamma$-valerolactone (M6) and phenolic acids by enzymes of the colonic microflora [5;6]. Gallic acid has been identified in mouse fecal matter as breakdown metabolite of BT [7]. In human urine Hodgson et al. have identified BT specific metabolites such as 3-O-methylgallic acid (3OMGA), 4-O-methylgallic acid (4OMGA) and 3,4-O-dimethylgallic acid [2]. Potential metabolites of the theaflavins and thearubigins however are still under investigation [7]. Most metabolites are absorbed, conjugated to the glucuronidated and sulfated form, and transported to the blood and excreted in the urine [8;9]. Upon absorption, GTPs and catechol containing phenolic acids undergo methylation, catalyzed by the enzyme catechol-O-methyltransferase (COMT), which alters their biological activity [10]. The health benefits of tea have been primarily ascribed to their GTP content [11]. Since the concentration of monomeric GTPs in BT is relatively low, it is assumed that the phenolic breakdown products of polymeric polyphenols contribute to the health benefits of BT such as reduced risk of cardiovascular disease and stroke [12;13]. Possible interactions and possible enhancement of the biological activity of intestinal phenolic acid products has not been investigated in detail. Previous work from our laboratory and others demonstrated that the catechol containing 3,4-DHPAA exhibited antiproliferative and antioxidant activity in vitro [14;15]. Other phenolic acids, without the catechol or hydroxyl groups attached to the ring structure, did not exhibit considerable activities $[14 ; 15]$. It was the objective of the current investigation to assess whether the consumption of GT and BT can lead to concentrations of phenolic metabolites adequate to contribute to the health benefits of tea consumption. Serum and early morning void urine samples were available from prostate cancer patients, who consumed six cups daily of GT or BT for 3-6 weeks as part of a phase II clinical prostatectomy trial [10].

Colorectal cancer is a major cause of cancer-related mortality in both men and women [16]. There is increased scientific interest in the potential of dietary substances for prevention of colon cancer [17]. The colonic microflora has been suggested to play a critical role in maintaining a healthy bowel and lowering the risk of colorectal cancer [18]. The interaction between the diet and the microbiome is complex. Bacteria can influence cancer risk by metabolizing dietary components and dietary components can influence the composition and activity of the microbiome [19]. The purpose of our investigations was to quantify the bacterial metabolites of green and black tea polyphenols and to determine the biological activity of these metabolites. Work by Jenner et al determined that the concentration of the major phenolics in human fecal water was in the range of $46-479 \mu \mathrm{mol} / \mathrm{L}$ each, which is 
much greater than the maximum plasma concentrations of 1-2 $\mu \mathrm{mol} / \mathrm{L}$ [20]. Therefore we expect that colonic phenolic breakdown products will contribute to the health benefit of tea in the digestive system and we selected colon cancer cells for our in vitro investigations. Since the colon contains a mixture of different phenolic acids and parent polyphenols we investigated in vitro the antiproliferative activity and interaction of EGCG and 3,4-DHPAA.

\section{MATERIALS AND METHODS}

\section{GT and BT intervention in men diagnosed with prostate cancer}

As part of an ongoing clinical study to investigate the effect of tea consumption on prostate cancer, serum and urine samples were collected for the analysis of phenolic breakdown products of tea polyphenols. Details of the trial have been described previously [10]. The following protocol was approved by the UCLA and Veterans Administration human subjects' committees and informed consent was signed by all study subjects (IRB\#10-001050). The clinical trial is registered as NCI-2010-00973. At the time of the phenolic acid analysis 82 men with clinically localized prostate cancer were randomized to 6 cups daily of green tea, black tea or water for 3 to 6 weeks prior to undergoing radical prostatectomy. Thirteen withdrew and 69 men completed the intervention (24 in control group and 23 in GT and 22 BT group). Subjects randomized to the tea groups received detailed instructions to prepare the tea using 1 tea bag in $240 \mathrm{ml}$ of boiling water to be brewed for $5 \mathrm{~min}$. GT bags (authentic GT) were provided by Celestial Seasonings (Boulder, $\mathrm{CO}$ ) and BT bags (English Breakfast tea) were purchased from Twinings (Clifton, NJ). All tea bags were from the same production lot number. The control group was instructed to consume 6 cups of water daily. A tea consumption diary was kept to record compliance. A fasting urine sample was collected at baseline and two first void urine samples during the intervention. Fasting blood was collected before the intervention and the morning of the surgery.

\section{Polyphenol analysis of GT and BT}

Tea was brewed by steeping one tea bag in $240 \mathrm{~mL}$ of boiling water for $5 \mathrm{~min}$. The GTP composition was determined by HPLC with CoulArray electrochemical detection (ESA, Chelmsford, MA) as previously described [21].

\section{Phenolic acids, valerolactone and hippuric acid analysis}

Serum and urinary phenolic acids and polyhydroxyphenyl- $\gamma$-valerolactones (M4 and M6) were quantified according to the protocol described previously for plasma and urinary flavanol analysis [22] with minor modifications. Briefly, $200 \mu \mathrm{l}$ of serum and urine samples were incubated with glucuronidase (500 U, G7896, Sigma-Aldrich, St. Louis, MI) and sulfatase (40 U, S9754, Sigma-Aldrich) to release the free forms from conjugates. Serum was deproteinized with repeated treatments of $400 \mu \mathrm{L}$ of methylene chloride and $300 \mu \mathrm{l}$ of water. The aqueous phase was pooled and acidified to $\mathrm{pH} 3$ with $1 \mathrm{~N}$ hydrochloric acid for ethyl acetate extraction. Urine was extracted twice with $800 \mu l$ of ethyl acetate directly after acidification. The extract was vacuum dried and reconstituted. Urinary hippuric acid concentration was determined by injecting urine directly after appropriate dilution (10-1000 folds with water). Phenolic acid M4 and M6 concentrations were determined by HPLC with CoulArray electrochemical detection (ESA, Chelmsford, MA) as previously described [21;22] and hippuric acid by LC-MS/MS (Thermo Finnigan, San Jose, CA) according to Penner et al. [23]. Urinary phenolic acids, M4 and M6, and hippuric acid concentrations were quantified according to their standard curves and adjusted by urinary creatinine concentration. All HPLC grade solvents were purchased from Fisher Scientific (Pittsburgh, PA). 3-hydroxyphenylacetic acid (3-HPAA), 4-hydroxyphenylacetic acid (4-HPAA), 3,4DHPAA, 3-methoxy-4-hydroxyphenylacetic acid (3M4-HPAA, 3OMGA (3,4-dihydroxy-5- 
methoxybenzoic acid), 4OMGA (3,5-dihydroxy-4-methoxybenzoic acid) and hippuric acid were purchased from Sigma-Aldrich. A defined laboratory urine standard, with known quantities of the 5-( $3^{\prime}, 4^{\prime}, 5^{\prime}$-trihydroxyphenyl)- $\gamma$-valerolactone (M4) and 5-( $3^{\prime}, 4^{\prime}$ dihydroxy)- $\gamma$-valerolactone (M6) concentrations and known retention times were generously provided by the laboratory of C.S. Yang [24]. The quantities of the valerolactones in this standard were determined by LC-MS/MS [24]. Urinary creatinine was determined using the colorimetric creatinine Liquicolor ${ }^{\circledR}$ kit (Stanbio Laboratory, Boerne, TX) according to manufacturer's instructions.

\section{Total phenolic content analysis}

The total phenolic content was determined according to the Folin-Ciocalteau method [25]. Brewed GT and BT were diluted 1:5 with methanol-water (1:1). $20 \mu \mathrm{L}$ of sample was incubated with $300 \mu \mathrm{L}$ of methanol-water (1:1) and $20 \mu \mathrm{L}$ of Folin-Ciocalteau reagent for 10 min at $25^{\circ} \mathrm{C}$. $60 \mu \mathrm{l}$ of $20 \% \mathrm{Na}_{2} \mathrm{CO}_{3}$ solution was added to each tube and mixed well. Tubes were further incubated for $20 \mathrm{~min}$ at $40 \mathrm{oC}$. After incubation, samples were immediately cooled in an ice bath to room temperature. Samples and standards (gallic acid) were processed identically. The absorbance was determined at $755 \mathrm{~nm}$ (VersaMax microplate reader, Molecular Devices, Sunnyvale, CA) and final results calculated from the standard curve.

\section{Cell culture experiment}

HCT116 colon cancer cells were grown in McCoys5A medium supplemented with 10\% fetal bovine serum (FBS) and $1 \%$ penicillin-streptomycin. Cells were maintained below passage 15 and were seeded into 96 -well plate at a density of $1 \times 10^{4}$ cells/well $(100 \mu l)$ and incubated for 28 hours in $37^{\circ} \mathrm{C}, 5 \% \mathrm{CO}_{2}$ to allow cell attachment. After cells attached, cells were treated with the following: vehicle control (dimethylsulfoxide, DMSO), EGCG at $40 \mu \mathrm{mol} / \mathrm{L}, 3,4-\mathrm{DHPAA}$ at 100,200 , and $300 \mu \mathrm{mol} / \mathrm{L}, 3 \mathrm{M} 4-\mathrm{HPAA}$ at 100 and $200 \mu \mathrm{mol} / \mathrm{L}$, co-treatment of 40 $\mu \mathrm{mol} / \mathrm{L}$ EGCG with 100, 200 and 300 $\mu \mathrm{mol} / \mathrm{L}$ 3,4-DHPAA. Stock solutions of EGCG, 3,4-DHPAA, and 3M4-HPAA were prepared in DMSO at concentrations of $100 \mathrm{mM}, 200 \mathrm{mM}$ and $200 \mathrm{mM}$, respectively. 3OMGA, 4OMGA, 3-HPAA, 4-HPAA, HA, and 3M4-HPAA were tested at 50, 100, 200, 300 and $400 \mu \mathrm{mol} / \mathrm{L}$. At a pH of 6.5 or above EGCG undergoes dimerization, producing hydrogen peroxide $\left(\mathrm{H}_{2} \mathrm{O}_{2}\right)$ [26]. To avoid the effect of $\mathrm{H}_{2} \mathrm{O}_{2}$, catalase was added to the medium at $50 \mathrm{U} / \mathrm{ml} 5 \mathrm{~min}$ prior to the addition of EGCG. All treatments were normalized to $0.2 \%$ DMSO. The antiproliferative effect of treatments was determined after $24 \mathrm{hr}$ using the CellTiter-Glo® Luminescent Cell Viability Assay kit (Promega Corporation, Madison, WI) to determine ATP production following the manufacturer's instruction by reading the luminescence on a SpectraMax GeminiEM Microplate Reader (Molecular Devices, Sunnyvale, CA). All experiments were done in triplicates.

\section{Methylation of EGCG and 3,4-DHPAA}

HCT116 cells were grown in $60 \mathrm{~mm}$ dishes for 2 or 24 hours with $60 \mu \mathrm{mol} / \mathrm{L}$ of EGCG, 100 $\mu \mathrm{mol} / \mathrm{L}$ of 3,4-DHPAA or co-treatment of EGCG with 3,4-DHPAA at the same concentration. Cells were washed, harvested, lysed and intracellular concentration determined by HPLC with Coularray electrochemical detection as described previously [10]. Cytosolic protein concentration was determined using the Bio-Rad protein assay according to the manufacturer's protocol (Bio-Rad Laboratories, Hercules, CA).

\section{Determination of COMT activity}

Cells were cultured in $60 \mathrm{~mm}$ Petri dishes and treated with $60 \mu \mathrm{mol} / \mathrm{L}$ of EGCG as used for the bioavailability assay. After $2 \mathrm{~h}$ or $24 \mathrm{~h}$ the cells were harvested and COMT activity was 
measured followed the procedures described by Reenilä et al [27] with some modifications. Briefly, medium was removed and the dishes were washed with $5 \mathrm{ml}$ of cold PBS for 3 times. The cells were collected and homogenized in $10 \mathrm{mM} \mathrm{Na}_{2} \mathrm{HPO}_{4}$ buffer $(\mathrm{pH} 7.4)$ containing $0.5 \mathrm{mM}$ DTT. The homogenates were centrifuged at $900 \times \mathrm{g}$ for $10 \mathrm{~min}$ at $4{ }^{\circ} \mathrm{C}$ and protein concentrations in the supernatant were measured by the Bio-Rad protein assay following the manufacturer's protocol (Bio-Rad Laboratories). The supernatants were stored at $-70^{\circ} \mathrm{C}$ until use. The COMT activity was evaluated based on the formation of the methyl metabolite vanillic acid (3-methoxy-4-hydroxybenzoic acid) of dihydroxybenzoic acid (DHBAc) catalyzed by COMT. Briefly, the cell preparation containing $100 \mu \mathrm{g}$ protein was incubated at $37^{\circ} \mathrm{C}$ with $0.2 \mathrm{mM} \mathrm{S}$-adenosyl-L-methionine iodide (AdoMet) (Sigma Chemicals), $5 \mathrm{mM} \mathrm{MgCl} 2$, and $200 \mu \mathrm{M}$ DHBAc, buffered with $100 \mathrm{mM} \mathrm{Na}_{2} \mathrm{HPO}_{4}$ buffer (pH 7.4 ) in a total volume of $125 \mu \mathrm{l}$. After $30 \mathrm{~min}$, the reaction was terminated by adding $25 \mu \mathrm{l}$ of $4 \mathrm{M}$ perchloric acid. Protein was removed by centrifuge at $14,000 \mathrm{rpm}$ for $15 \mathrm{~min}$, and the supernatant was detected by HPLC-CoulArray detection system for vanillic acid which had a main peak at $500 \mathrm{mV}$. The COMT enzyme activity was expressed as nmol vanillic acid formed $/ \mathrm{h} / \mathrm{mg}$ protein. The experiment was performed in triplicate.

\section{Statistical Analysis}

All statistical analyses were conducted using the SAS statistical software package version 9.2, 2008 (SAS Institute, Cary, NC). Mean values and standard deviations were calculated using descriptive statistics. We evaluated baseline differences using ANOVA with multiple pair-wise comparisons for continuous variables and chi-square cross-tabulation analysis for comparisons of categorical variables. To assess treatment group effects, we conducted repeated measures analysis of variance (rANOVA) models that simultaneously estimated within subject change from baseline and between group differences. We constructed contrasts that compared GT to control and BT to control. The rANOVA models of serum variables utilized two time points, baseline and post intervention, while models of urinary variables utilized three time points: baseline, week 2 and week 3. Reported p-values are based on the rANOVA time by group interactions. Differences between the antiproliferative activity of the individual phenolic metabolites and in combination compared to the vehicle control were determined using ANOVA. Student's t-test was used to compare the intracellular concentration of 3,4-DHPAA and methylated 3,4-DHPAA after treatment with 3,4-DHPAA alone or in combination with EGCG.

\section{RESULTS}

\section{Baseline Differences}

At baseline there was no significant difference in age, race, body composition, compliance, days of intervention, and number and type of medication between intervention and control groups (Table 1).

\section{Total phenolic content of GT and BT}

The consumption of six cups of GT provided a total of $1027 \mathrm{mg}$ GTPs $(2659 \mu \mathrm{mol}), 17 \mathrm{mg}$ gallic acid, with a total of $1215 \mathrm{mg}$ gallic acid equivalents (GAE), whereas BT contained a total of $82 \mathrm{mg}$ GTPs (about $205 \mu \mathrm{mol}), 344 \mathrm{mg}$ gallic acid, $35 \mathrm{mg}$ of THE $(49 \mu \mathrm{mol})$ with a total of $940 \mathrm{mg}$ GAE (Table 2).

\section{Serum and urine phenolic metabolites and hippuric acid concentrations}

Fasting serum was collected at baseline visit and prior to surgery at early morning in the hospital. Fasting urine was collected at baseline and twice during the intervention as first void urine. The analysis of urine from men consuming six cups of GT, BT or water for 3-6 
weeks demonstrated that all four phenolic acids, the two valerolactone metabolites as well as hippuric acid were excreted in urine (Figure 1). Among the phenolic acids 4-HPAA was present in the highest concentration in urine of the control group followed by 3,4-DHPAA, 3M4-HPAA and 3-HPAA. Urine concentrations of 4-HPAA ( $\mathrm{p}=0.04)$ and 3-HPAA $(\mathrm{p}=0.002)$ increased significantly following GT consumption. Urinary 3,4-DHPAA $(\mathrm{p}=0.07)$ showed a marginal significant increase, while 3M4-HPAA $(\mathrm{p}=0.14)$ and hippuric acid $(\mathrm{p}=0.13)$ showed an increasing trend following the GT consumption (Figure 1). The urine concentrations of M4 and M6 (M4: $\mathrm{p}=0.005 ; \mathrm{M} 6$ : $\mathrm{p}=0.002$ ) were significantly increased after GT consumption (Figure 1F and G). 3MOGA was highly specific for BT consumption and was increased significantly in 17 out of 22 men consuming BT and 3 out of 23 men consuming GT. 3MOGA was absent in urine from men consuming water. In urine from men consuming BT the urine concentration of all phenolic metabolites increased modestly over time, but did not reach significance. The mean change in excretion of hippuric acid from baseline due to drinking GT was $3058 \mu \mathrm{mol}$ (520 mg of hippuric acid) per day and the sum of the four phenolic acids was $96.5 \mu \mathrm{mol}$ per day (assuming a daily creatinine excretion of 2 g). While drinking BT, the mean change of hippuric acid was $1512 \mu \mathrm{mol}(257 \mathrm{mg}$ of hippuric acid) per day and the sum of the four phenolic acids was $69 \mu \mathrm{mol}$ per day (Figure $1)$.

While many serum phenolic acid concentrations did not change significantly according to intervention group compared to control (Table 3), the serum concentration of 3,4-DHPAA after GT and BT intervention and 4-HPAA after GT consumption increased significantly (Table 2). M4 and M6 and 3OMGA were not detected in blood except in one blood sample.

\section{Inhibition of cell proliferation of HCT116 colon cancer cells}

Screening the antiproliferative activity of all phenolic acids found in the urine we demonstrated that only EGCG and 3MOGA showed $\mathrm{IC}_{50}$ below $400 \mu \mathrm{mol} / \mathrm{L}$ (Table 4). We observed a significant increase in inhibition of proliferation of HCT116 colon cancer cells after treatment with EGCG and 3,4-DHPAA for 24 hours compared to vehicle control treatment (Figure 2). Treatment with the methylated form of 3,4-DHPAA (3M4-HPAA) did not inhibit proliferation. For the combination treatment concentrations below the inhibitory concentration of $50 \%\left(\mathrm{IC}_{50}\right)$ were chosen since the objective of the experiment was to determine the characteristics of co-treatment. The combination treatment of EGCG and 3,4DHPAA significantly increased the antiproliferative effect compared to the individual treatments.

\section{Intracellular metabolism of cotreatment of EGCG and 3,4-DHPAA}

HCT116 cells were treated with EGCG, 3,4-DHPAA or the combination of EGCG and 3,4DHPAA. The uptake of 3,4-DHPAA in HCT116 was much higher compared to EGCG and 3,4-DHPAA was present mainly in the methylated form (3M4-HPAA). After $24 \mathrm{~h}$ the content of methylated 3,4-DHPAA was doubled to $2238.2 \pm 69.3$ with $65.1 \pm 14.3$ pmol of 3,4-DHPAA per mg cytosolic protein remaining. The major effect of treatment of HCT116 cells with a combination of EGCG and 3,4-DHPAA for $2 \mathrm{~h}$ was a decrease in methylation of 3,4-DHPAA by $85 \%$ and significant increase in intracellular concentration of nonmethylated 3,4-DHPAA (Figure 3A). The intracellular uptake of EGCG after treatment with $60 \mu \mathrm{mol} / \mathrm{L}$ of EGCG was much lower compared to 3,4-DHPAA and was further decreased significantly with the combination treatment (Figure 3).

\section{Inhibition of COMT activity}

HCT116 colon cancer cells were incubated with $60 \mu \mathrm{mol} / \mathrm{L}$ of EGCG for 2 and $24 \mathrm{~h}$. After 2 and $24 \mathrm{~h}$ of EGCG treatment, COMT activity was inhibited by $65 \%(5.6 \mu \mathrm{mol} / \mathrm{L}$ of methylated end product compared to $15.7 \mu \mathrm{mol} / \mathrm{L}$ without EGCG). 


\section{DISCUSSION}

Tea may contribute to the prevention and treatment of chronic disease either directly through GTPs absorbed into the circulation and transported to the target tissues or indirectly through phenolic metabolites formed from GTPs by the colonic microflora. In a previous publication we reported the urinary and prostate tissue concentration of GTPs in 17 participants from the same tea intervention study in prostate cancer patients [10]. Here we demonstrate that the concentration and type of phenolic metabolites in serum and urine are significantly different after consumption of GT compared to BT for 3-6 weeks. After GT consumption we observed a significant increase in urinary concentrations of four out of eight phenolic metabolites and a trend to increase in three other phenolic metabolites. Whereas, after BT consumption, 3OMGA was increased significantly and we observed some non-significant increases in the other phenolic metabolites. Many of the phenolic metabolites are not specific markers of tea intake, since they were also present in urine from men in the water control group. Only 5 - $\left(3^{\prime}, 4^{\prime}, 5^{\prime}\right.$-trihydroxyphenyl)- $\gamma$-valerolactone (M4) was unique to the urine collected by men in the GT and BT intervention groups and 3OMGA in the BT group. M4, as described by Sang et al., is a specific marker of EGCG and (-)-epigallocatechin metabolism and therefore is tea specific [24]. These phenolic ring fission products have been described in pharmacokinetic studies appearing after 4 hours in the plasma and between 812 hours in urine [28;29]. Due to the high concentration excreted in association with tea consumption the M4 metabolite may provide an excellent marker of tea consumption to be used in epidemiological studies. For example in a prospective study of gastric, esophageal and colon cancer in men from the Shanghai study the excretion of the hydroxyphenyl- $\gamma$ valerolactones was highly correlated with tea intake [30;31]. Little is known about the biological activity of the hydroxyphenyl- $\gamma$-valerolactones. One study by Sanchez-Patan demonstrated that $5-\left(3^{\prime}, 4^{\prime}\right.$-dihydroxyphenyl)- $\gamma$-valerolactone (M6) exhibited about $60 \%$ of the antioxidant activity compared to catechin/epicatechin [32].

Our chemical analysis of BT found that gallic acid is present in high concentration (344 \pm 5.2 mg per six cups). In a previous study by Hodgson three gallic acid metabolites (3OMGA, 4OMGA and 3,4-O-dimethylgallic acid) were found to be increased significantly after the consumption of five cups of BT daily [2]. In our study presented here we found a significant increase in urinary $3 \mathrm{MOGA}$. The concentration of 3MOGA in serum was below the detection limit. Our proliferation assay in colon cancer cells demonstrated that 3OMGA exhibited the strongest antiproliferative activity among the phenolic acids tested, whereas 4OMGA did not inhibit cell growth. This further supports our hypothesis that phenolic compounds with a catechol group exhibit stronger antiproliferative activity since only 3OMGA but not 4OMGA has a catechol group.

Serum 3,4-DHPAA was increased significantly in serum after the GT and BT intervention and 4-HPAA after GT consumption. Future pharmacokinetic studies are needed to truly assess the serum concentrations of these phenolic metabolites. Although the increase noted in the concentration of serum 3,4-DHPAA and 4-HPAA was relatively small, it is possible that the sum of all phenolic acids may contribute to the beneficial health effect of tea.

Hippuric acid (N-benzoylglycine) is a hepatic conjugation product of colonic phenolic acids with glycine [33]. Hippuric acid has been demonstrated to be an important gut microbial cometabolite [33,34]. Urinary hippuric acid was much more increased in urine from men consuming GT compared to BT. However hippuric acid does not appear to be a specific marker of polyphenol intake from tea. Nevertheless, urinary levels of hippurate have been shown to correlate with obesity and hypertension and were decreased in patients with Type 2 Diabetes Mellitus [35-37]. 
The chemical source for the colonic phenolic acid formation differs between GT and BT. In BT the majority of phenolics are present in very large molecular size compounds such as thearubigins and have been demonstrated to contribute to the formation of hippuric acid [38]. The consumption of six cups of GT provided a total of $1215 \mathrm{mg}$ GAE, which was almost entirely composed of GTPs (1027 mg). In contrast BT contained a total of $940 \mathrm{mg}$ GAE, including $74 \mathrm{mg}$ GTPs, $35 \mathrm{mg}$ of THE and $344 \mathrm{mg}$ gallic acid. Based on this difference of GAE and monomeric polyphenols in BT we hypothesize that polymeric thearubigins contribute to the GAE and to the formation of phenolic acids and hippuric acid.

A large interindividual variability between the formation of phenolic metabolites and hippuric acid was observed, which possibly is based on differences in the individual intestinal species within the microflora. It has been demonstrated by Schantz et al. that the amount of phenolic acids generated by the microflora depends on the composition of the microbiome [39]. For example they demonstrated that a difference in microbiome composition of ileostomy content was associated with a significant difference in degradation of tea flavanols [39]. Another study by Lee et al provided evidence that GTPs significantly alter the composition of the intestinal bacterial population [40].

Similar urinary phenolic acid concentrations as found in our analyses were found by a study by Olthof et al. [15] following administration of a single dose of $4 \mathrm{~g}$ of BT solids (Unilever Research, Vlaardingen, Netherlands) containing $4.3 \mathrm{mmol}$ phenols as monomeric equivalents equivalent to $2 \mathrm{~L}$ of strong BT daily for 7 days [15]. A significant increase over placebo intervention was found for 3-HPAA $(68 \pm 6 \mu \mathrm{mol} / 24 \mathrm{~h}), 3,4$-DHPAA $(26 \pm 2 \mu \mathrm{mol} / 24$ h) and hippuric acid $(4400 \pm 400 \mu \mathrm{mol} / 24 \mathrm{~h})$, [15]. Other phenolic acids found were vanillic and homovanillic acid $[15 ; 41]$.

We demonstrated that 3MOGA had the strongest antiproliferative activity followed by 3,4DHPAA in HCT116 colon cancer cells among the phenolic acids found in serum and urine [14]. It appears that the catechol group is important to the biological activity. The IC50 concentrations of EGCG and the phenolic acids found to inhibit the proliferation of HCT116 colon cancer cells were relatively high compared to other published data. Most likely the catalase-treatment used in our cell culture experiments to avoid the hydrogen peroxide effect, contributed to the high IC50 concentrations [42]. Lower, noncytotoxic concentrations of 3,4DHPAA and 3-(3,4-dihydroxyphenyl)-propionic acid were effective in inhibiting enzymes involved in detoxification (GSTT2) and inflammation (COX-2) [43]. In addition although the concentration of each intestinal phenolic metabolite may not be high enough to exhibit significant biological activity, it is our hypothesis that the combined activity of the phenolic metabolites and parent polyphenols will increase the antiproliferative activity in the colon. In the current in vitro study we demonstrated that the combination of EGCG and 3,4DHPAA significantly increased the antiproliferative activity compared to treatment with EGCG or DHPAA alone. In HCT116 cells EGCG inhibited the COMT activity by $65 \%$ leading to a significant decrease of the intracellular concentration of methylated 3,4DHPAA. In methylated form, both EGCG and 3,4-DHPAA exhibit lower antiproliferative activity [44]. Therefore the decrease in 3,4-DHPAA methylation by cotreatment with EGCG may have led to the increase in antiproliferation.

The human COMT has a low substrate specificity, and can catalyze the $O$-methylation of various catechol-containing endobiotics and xenobiotics [44]. It has been demonstrated that certain catechol containing flavonoids such as EGCG and quercetin inhibit COMT activity [45]. Enzymatic studies by Zhu et al and Nagai et al. demonstrated that EGCG is an exceptional strong COMT inhibitor with an $\mathrm{IC}_{50}$ of $50 \mathrm{nmol} / \mathrm{L}$ in comparison to phenolic acids from coffee such as chlorogenic acid $\left(\mathrm{IC}_{50}=1.4 \mu \mathrm{mol} / \mathrm{L}\right)$ and caffeic acid $\left(\mathrm{IC}_{50}=6-12\right.$ $\mu \mathrm{mol} / \mathrm{L}$ ) [46;47]. Our observation that EGCG strongly inhibited the methylation of 3,4- 
DHPAA over its own methylation is supporting the fact that EGCG is a stronger COMT inhibitor compared to 3,4-DHPAA.

In summary, we found that the GT-specific urinary phenolic marker $\left(5-\left(3^{\prime}, 4^{\prime}, 5^{\prime}\right.\right.$ trihydroxyphenyl)- $\gamma$-valerolactone) and BT-specific marker (3OMGA) were increased significantly after the consumption of six cups of GT or BT compared to water control. Serum phenolic acids showed smaller increases after consumption of GT and BT. Metabolic interactions between the intestinal phenolic acid product 3,4-DHPAA with its parent compound EGCG may enhance the biological potency of tea in the colon. Future preclinical studies are warranted to evaluate potential chemopreventative and/or anticancer effects of green tea in colon cancer models.

\section{Acknowledgments}

This work was supported by the National Institutes of Health [RO1 CA116242] and [P50CA92131].

\section{Abbreviations}

$\begin{array}{ll}\text { 3,4-DHPAA } & \text { 3,4-dihydroxyphenylacetic acid } \\ \text { 4-HPAA } & \text { 4-hydroxyphenylacetic acid } \\ \text { 3-HPAA } & \text { 3-hydroxyphenylacetic acid } \\ \text { 3M4-HPAA } & \text { 3-methoxy-4-hydroxyphenylacetic acid } \\ \text { 3OMGA } & \text { 3-O-methyl gallic acid } \\ \text { 4OMGA } & \text { 4-O-methylgallic acid } \\ \text { BT } & \text { black tea } \\ \text { COMT } & \text { catechol-O-methyltransferase } \\ \text { EGCG } & \text { (-)-epigallocatechin gallate } \\ \text { GAE } & \text { gallic acid equivalent } \\ \text { GT } & \text { Green tea } \\ \text { GTP } & \text { green tea polyphenol } \\ \text { M4 and M6 } & \text { polyhydroxyphenyl- } \gamma \text {-valerolactones } \\ \text { THE } & \text { theaflavin }\end{array}$

\section{References}

1. Sharma V, Rao LJ. A thought on the biological activities of black tea. Crit Rev Food Sci Nutr. 2009; 49:379-404. [PubMed: 19399668]

2. Hodgson JM, Morton LW, Puddey IB, Beilin LJ, Croft KD. Gallic acid metabolites are markers of black tea intake in humans. J Agric Food Chem. 2000; 48:2276-2280. [PubMed: 10888536]

3. Kuhnert N, Drynan JW, Obuchowicz J, Clifford MN, Witt M. Mass spectrometric characterization of black tea thearubigins leading to an oxidative cascade hypothesis for thearubigin formation. Rapid Commun Mass Spectrom. 2010; 24:3387-3404. [PubMed: 21072794]

4. Mulder TP, van Platerink CJ, Wijnand Schuyl PJ, Van Amelsvoort JM. Analysis of theaflavins in biological fluids using liquid chromatography-electrospray mass spectrometry. J Chromatogr B Biomed Sci Appl. 2001; 760:271-279. [PubMed: 11530986]

5. Li C, Meng X, Winnik B, Lee MJ, Lu H, Sheng S, Buckley B, Yang CS. Analysis of urinary metabolites of tea catechins by liquid chromatography/electrospray ionization mass spectrometry. Chem Res Toxicol. 2001; 14:702-707. [PubMed: 11409941] 
6. Li C, Lee MJ, Sheng S, Meng X, Prabhu S, Winnik B, Huang B, Chung JY, Yan S, Ho CT, Yang CS. Structural identification of two metabolites of catechins and their kinetics in human urine and blood after tea ingestion. Chem Res Toxicol. 2000; 13:177-184. [PubMed: 10725114]

7. Chen H, Parks TA, Chen X, Gillitt ND, Jobin C, Sang S. Structural identification of mouse fecal metabolites of theaflavin 3,3' -digallate using liquid chromatography tandem mass spectrometry. J Chromatogr A. 2011; 1218:7297-7306. [PubMed: 21906744]

8. Henning SM, Choo JJ, Heber D. Nongallated compared with gallated flavan-3-ols in green and black tea are more bioavailable. J Nutr. 2008; 138:1529S-1534S. [PubMed: 18641202]

9. Lambert JD, Sang S, Yang CS. Biotransformation of green tea polyphenols and the biological activities of those metabolites. Mol Pharm. 2007; 4:819-825. [PubMed: 17963356]

10. Wang P, Aronson WJ, Huang M, Zhang Y, Lee RP, Heber D, Henning SM. Green tea polyphenols and metabolites in prostatectomy tissue: implications for cancer prevention. Cancer Prev Res (Phila). 2010; 3:985-993. [PubMed: 20628004]

11. Yang CS, Wang X, Lu G, Picinich SC. Cancer prevention by tea: animal studies, molecular mechanisms and human relevance. Nat Rev Cancer. 2009; 9:429-439. [PubMed: 19472429]

12. Bohn SK, Ward NC, Hodgson JM, Croft KD. Effects of tea and coffee on cardiovascular disease risk. Food Funct. 2012; 3:575-591. [PubMed: 22456725]

13. Arab L, Liu W, Elashoff D. Green and black tea consumption and risk of stroke: a meta-analysis. Stroke. 2009; 40:1786-1792. [PubMed: 19228856]

14. Gao K, Xu A, Krul C, Venema K, Liu Y, Niu Y, Lu J, Bensoussan L, Seeram NP, Heber D, Henning SM. Of the major phenolic acids formed during human microbial fermentation of tea, citrus, and soy flavonoid supplements, only 3,4-dihydroxyphenylacetic acid has antiproliferative activity. J Nutr. 2006; 136:52-57. [PubMed: 16365058]

15. Olthof MR, Hollman PC, Buijsman MN, van Amelsvoort JM, Katan MB. Chlorogenic acid, quercetin-3-rutinoside and black tea phenols are extensively metabolized in humans. J Nutr. 2003; 133:1806-1814. [PubMed: 12771321]

16. Siegel R, Naishadham D, Jemal A. Cancer statistics, 2012. CA Cancer J Clin. 2012; 62:10-29. [PubMed: 22237781]

17. Pan MH, Lai CS, Wu JC, Ho CT. Molecular mechanisms for chemoprevention of colorectal cancer by natural dietary compounds. Mol Nutr Food Res. 2011; 55:32-45. [PubMed: 21207511]

18. O'Keefe SJ. Nutrition and colonic health: the critical role of the microbiota. Curr Opin Gastroenterol. 2008; 24:51-58. [PubMed: 18043233]

19. Davis CD, Milner JA. Gastrointestinal microflora, food components and colon cancer prevention. J Nutr Biochem. 2009; 20:743-752. [PubMed: 19716282]

20. Jenner AM, Rafter J, Halliwell B. Human fecal water content of phenolics: the extent of colonic exposure to aromatic compounds. Free Radic Biol Med. 2005; 38:763-772. [PubMed: 15721987]

21. Henning SM, Niu Y, Lee NH, Thames GD, Minutti RR, Wang H, Go VL, Heber D. Bioavailability and antioxidant activity of tea flavanols after consumption of green tea, black tea, or a green tea extract supplement. Am J Clin Nutr. 2004; 80:1558-1564. [PubMed: 15585768]

22. Hudthagosol C, Haddad EH, McCarthy K, Wang P, Oda K, Sabate J. Pecans acutely increase plasma postprandial antioxidant capacity and catechins and decrease LDL oxidation in humans. J Nutr. 2011; 141:56-62. [PubMed: 21106921]

23. Penner N, Ramanathan R, Zgoda-Pols J, Chowdhury S. Quantitative determination of hippuric and benzoic acids in urine by LC-MS/MS using surrogate standards. J Pharm Biomed Anal. 2010; 52:534-543. [PubMed: 20149566]

24. Sang S, Lee MJ, Yang I, Buckley B, Yang CS. Human urinary metabolite profile of tea polyphenols analyzed by liquid chromatography/electrospray ionization tandem mass spectrometry with data-dependent acquisition. Rapid Commun Mass Spectrom. 2008; 22:1567-1578. [PubMed: 18433082]

25. Singleton VL, Esau P. Phenolic substances in grapes and wine, and their significance. Adv Food Res Suppl. 1969; 1:1-261. [PubMed: 4902344]

26. Neilson AP, Hopf AS, Cooper BR, Pereira MA, Bomser JA, Ferruzzi MG. Catechin Degradation with Concurrent Formation of Homo- and Heterocatechin Dimers during in Vitro Digestion. J Agric Food Chem. 2007; 55:8941-8949. [PubMed: 17924707] 
27. Reenila I, Tuomainen P, Mannisto PT. Improved assay of reaction products to quantitate catecholO-methyltransferase activity by high-performance liquid chromatography with electrochemical detection. J Chromatogr B Biomed Appl. 1995; 663:137-142. [PubMed: 7704200]

28. Lee MJ, Maliakal P, Chen L, Meng X, Bondoc FY, Prabhu S, Lambert G, Mohr S, Yang CS. Pharmacokinetics of tea catechins after ingestion of green tea and (-)-epigallocatechin-3-gallate by humans: formation of different metabolites and individual variability. Cancer Epidemiol Biomarkers Prev. 2002; 11:1025-1032. [PubMed: 12376503]

29. Del RD, Calani L, Cordero C, Salvatore S, Pellegrini N, Brighenti F. Bioavailability and catabolism of green tea flavan-3-ols in humans. Nutrition. 2010; 26:1110-1116. [PubMed: 20080030]

30. Yuan JM, Gao YT, Yang CS, Yu MC. Urinary biomarkers of tea polyphenols and risk of colorectal cancer in the Shanghai Cohort Study. Int J Cancer. 2007; 120:1344-1350. [PubMed: 17149697]

31. Sun CL, Yuan JM, Lee MJ, Yang CS, Gao YT, Ross RK, Yu MC. Urinary tea polyphenols in relation to gastric and esophageal cancers: a prospective study of men in Shanghai, China. Carcinogenesis. 2002; 23:1497-1503. [PubMed: 12189193]

32. Sanchez-Patan F, Chioua M, Garrido I, Cueva C, Samadi A, Marco-Contelles J, Moreno-Arribas MV, Bartolome B, Monagas M. Synthesis, analytical features, and biological relevance of 5-(3', $4^{\prime}$-dihydroxyphenyl)-gamma-valerolactone, a microbial metabolite derived from the catabolism of dietary flavan-3-ols. J Agric Food Chem. 2011; 59:7083-7091. [PubMed: 21627328]

33. Phipps AN, Stewart J, Wright B, Wilson ID. Effect of diet on the urinary excretion of hippuric acid and other dietary-derived aromatics in rat A complex interaction between diet, gut microflora and substrate specificity. Xenobiotica. 1998; 28:527-537. [PubMed: 9622854]

34. Roowi S, Stalmach A, Mullen W, Lean ME, Edwards CA, Crozier A. Green tea flavan-3-ols: colonic degradation and urinary excretion of catabolites by humans. J Agric Food Chem. 2010; 58:1296-1304. [PubMed: 20041649]

35. Holmes E, Loo RL, Stamler J, Bictash M, Yap IK, Chan Q, Ebbels T, De IM, Brown IJ, Veselkov KA, Daviglus ML, Kesteloot H, Ueshima H, Zhao L, Nicholson JK, Elliott P. Human metabolic phenotype diversity and its association with diet and blood pressure. Nature. 2008; 453:396-400. [PubMed: 18425110]

36. Salek RM, Maguire ML, Bentley E, Rubtsov DV, Hough T, Cheeseman M, Nunez D, Sweatman BC, Haselden JN, Cox RD, Connor SC, Griffin JL. A metabolomic comparison of urinary changes in type 2 diabetes in mouse, rat, and human. Physiol Genomics. 2007; 29:99-108. [PubMed: 17190852]

37. Calvani R, Miccheli A, Capuani G, Tomassini MA, Puccetti C, Delfini M, Iaconelli A, Nanni G, Mingrone G. Gut microbiome-derived metabolites characterize a peculiar obese urinary metabotype. Int J Obes (Lond). 2010; 34:1095-1098. [PubMed: 20212498]

38. Clifford MN, Copeland EL, Bloxsidge JP, Mitchell LA. Hippuric acid as a major excretion product associated with black tea consumption. Xenobiotica. 2000; 30:317-326. [PubMed: 10752646]

39. Schantz M, Erk T, Richling E. Metabolism of green tea catechins by the human small intestine. Biotechnol J. 2010; 5:1050-1059. [PubMed: 20931601]

40. Lee HC, Jenner AM, Low CS, Lee YK. Effect of tea phenolics and their aromatic fecal bacterial metabolites on intestinal microbiota. Res Microbiol. 2006; 157:876-884. [PubMed: 16962743]

41. van Dorsten FA, Daykin CA, Mulder TP, van Duynhoven JP. Metabonomics approach to determine metabolic differences between green tea and black tea consumption. J Agric Food Chem. 2006; 54:6929-6938. [PubMed: 16939360]

42. Long LH, Kirkland D, Whitwell J, Halliwell B. Different cytotoxic and clastogenic effects of epigallocatechin gallate in various cell-culture media due to variable rates of its oxidation in the culture medium. Mutat Res. 2007; 634:177-183. [PubMed: 17851114]

43. Miene C, Weise A, Glei M. Impact of polyphenol metabolites produced by colonic microbiota on expression of COX-2 and GSTT2 in human colon cells (LT97). Nutr Cancer. 2011; 63:653-662. [PubMed: 21598179]

44. Bai HW, Shim JY, Yu J, Zhu BT. Biochemical and molecular modeling studies of the Omethylation of various endogenous and exogenous catechol substrates catalyzed by recombinant 
human soluble and membrane-bound catechol-O-methyltransferases. Chem Res Toxicol. 2007; 20:1409-1425. [PubMed: 17880176]

45. Nagai M, Conney AH, Zhu BT. Strong inhibitory effects of common tea catechins and bioflavonoids on the O-methylation of catechol estrogens catalyzed by human liver cytosolic catechol-O-methyltransferase. Drug Metab Dispos. 2004; 32:497-504. [PubMed: 15100171]

46. Zhu BT, Wang P, Nagai M, Wen Y, Bai HW. Inhibition of human catechol-O-methyltransferase (COMT)-mediated O-methylation of catechol estrogens by major polyphenolic components present in coffee. J Steroid Biochem Mol Biol. 2009; 113:65-74. [PubMed: 19095062] 


\section{Figure 1}

A

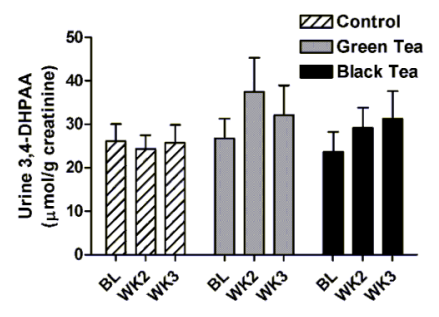

C

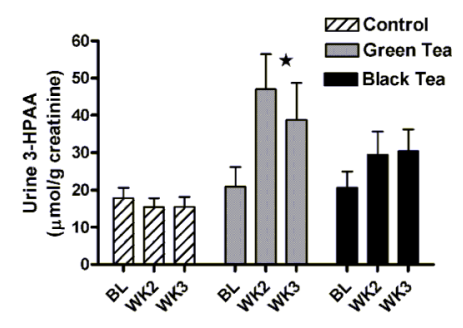

E

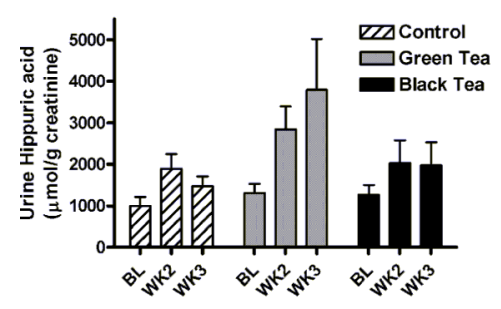

G

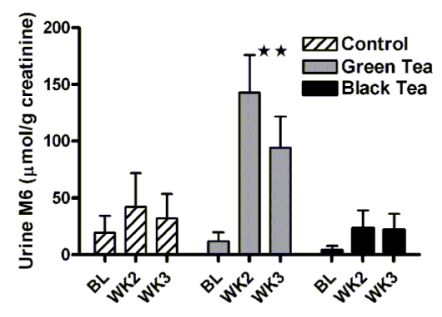

B

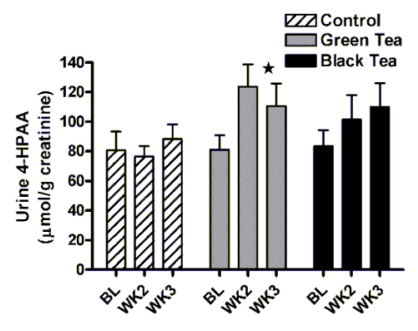

D

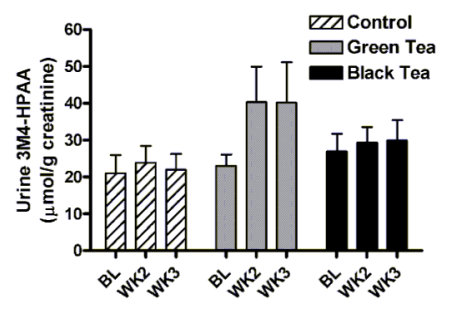

$\mathbf{F}$
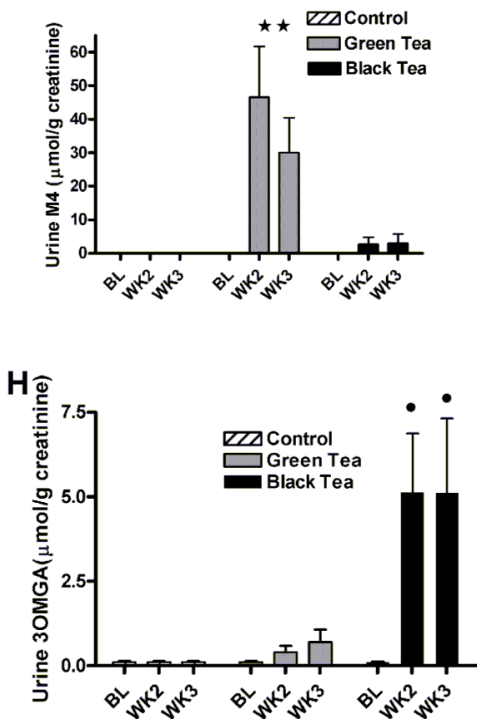

Figure 1.

Mean phenolic and hippuric acid concentrations in urine from men consuming 6 cups of GT, BT or water (mean \pm std). A) 3,4-DHPAA, B) 4-HPAA, C) 3-HPAA, D) 3M4-HPAA E) hippuric acid F) 5-( $3^{\prime}, 4^{\prime}, 5^{\prime}$-trihydroxyphenyl)- $\gamma$-valerolactone (M4); G) 5-( $3^{\prime}, 4^{\prime}$ dihydroxy- phenyl)- $\gamma$-valerolactone and H) 3-O-methyl gallic acid (3OMGA). Phenolic acids were analyzed by HPLC and hippuric acid by LC-MS/MS. Repeated measures analysis of variance was used to compare GT and BT to water intervention and time; mean \pm std; Number of participants: water $=24, \mathrm{GT}=23$ and $\mathrm{BT}=22 ; * \mathrm{p}<0.05 ; * * \mathrm{p}<0.001$; for $3 \mathrm{MeGA}$ we compared GT to BT intervention $\mathrm{p}<0.001$. 


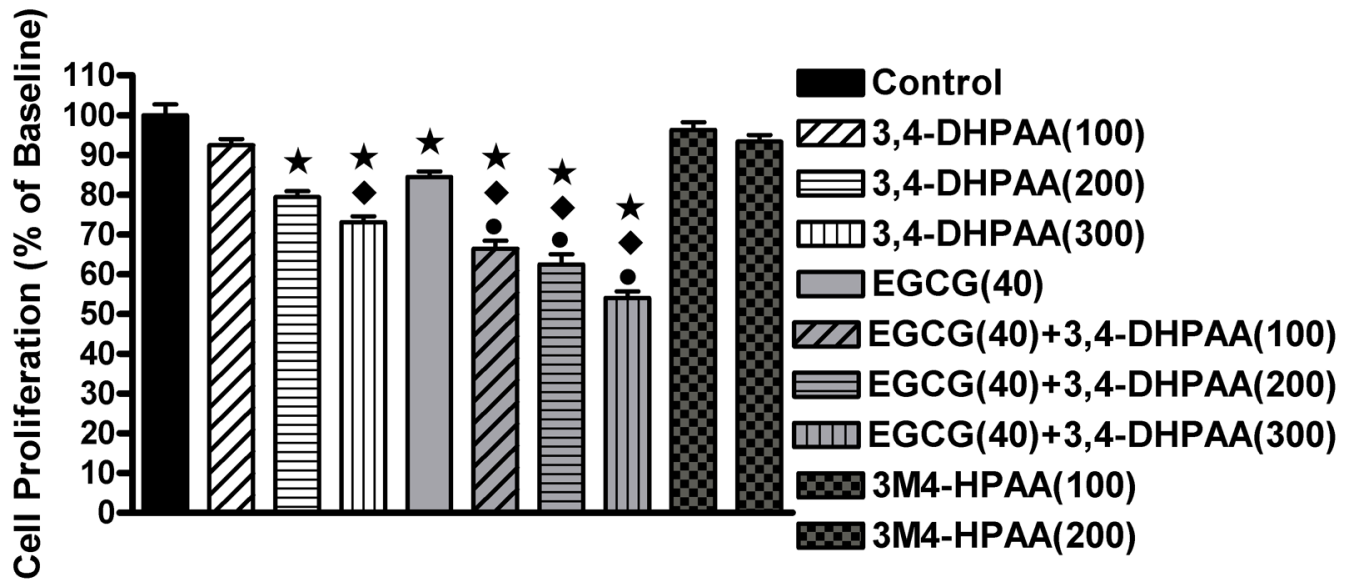

Figure 2.

Proliferation of HCT116 colon cancer cells. Concentrations indicated in parenthesis in $\mu \mathrm{mol} / \mathrm{L}$; means $\pm \mathrm{std} ; *$ significantly different from control, $\mathrm{p}<0.01,>$ significantly different from EGCG $40 \mu \mathrm{mol} / \mathrm{L}, \mathrm{p}<0.05$ and 1 significantly different from 3,4-DHPAA of same concentration, $\mathrm{p}<0.05$. 

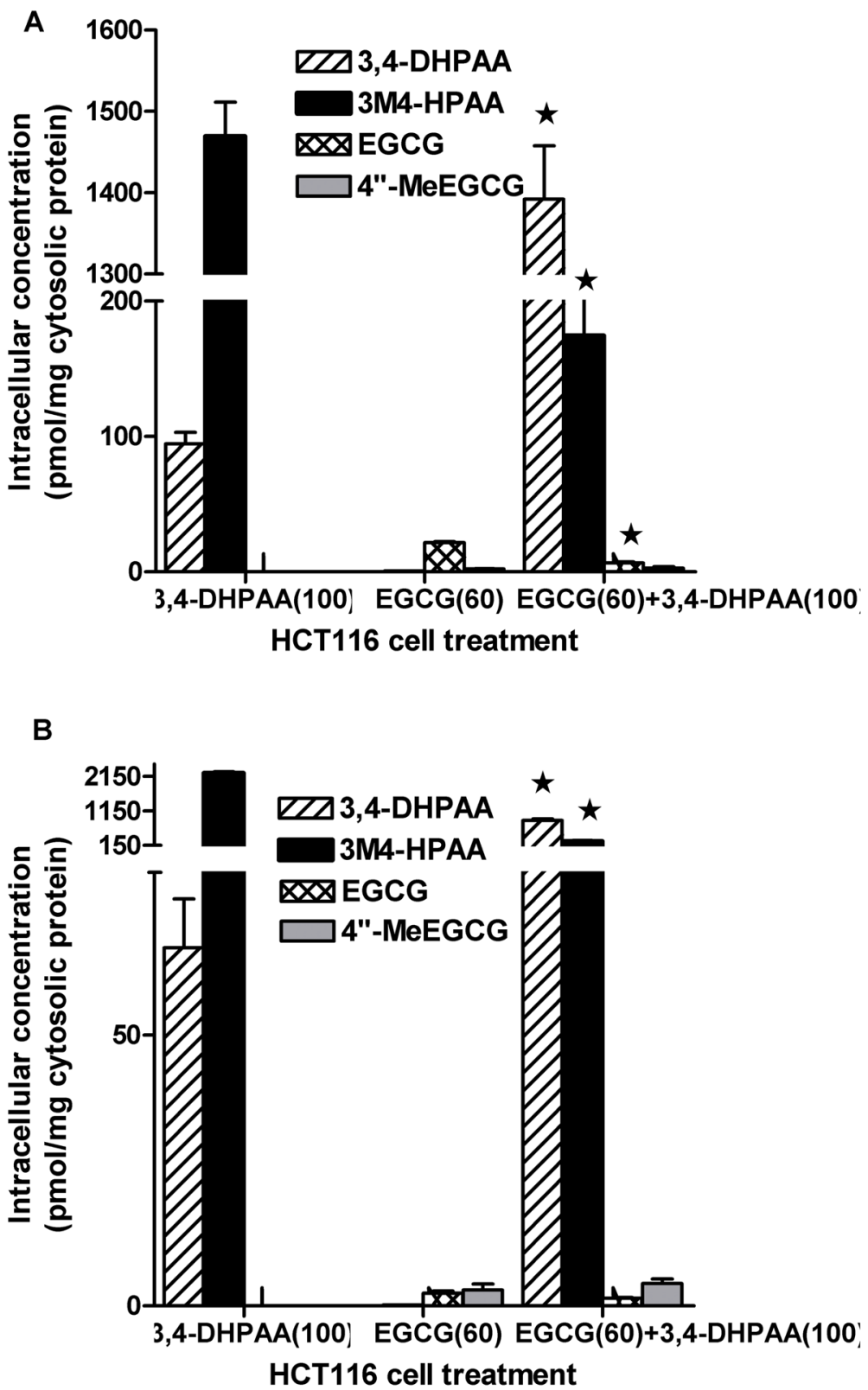

Figure 3.

Intracellular content of 3,4-DHPAA and EGCG A) after $2 \mathrm{~h}$ treatment with 3,4-DHPAA and EGCG alone or the combination of 3,4-DHPAA and EGCG; B) after $24 \mathrm{~h}$ treatment with the same compounds; concentrations indicated in parenthesis in $\mu \mathrm{mol} / \mathrm{L}$; mean \pm std; *combination treatment was significantly different to individual treatment; $\mathrm{p}<0.05$. 


\section{Table 1}

Characteristics of study population at baseline according to intervention groups

\begin{tabular}{lllll}
\hline & Control & GT & BT & p-value \\
\hline $\mathrm{N}$ & 24 & 23 & 22 & \\
Age & $62.1 \pm 5.7$ & $61.0 \pm 6.9$ & $62.0 \pm 7.5$ & 0.83 \\
Weight $(\mathrm{kg})$ & $87.7 \pm 15.7$ & $87.4 \pm 12.4$ & $88.6 \pm 13.7$ & 0.96 \\
Height $(\mathrm{m})$ & $1.8 \pm 0.08$ & $1.8 \pm 0.07$ & $1.8 \pm 0.07$ & 0.98 \\
BMI $\left(\mathrm{kg} / \mathrm{m}^{2}\right)$ & $27.4 \pm 4.9$ & $27.2 \pm 3.8$ & $27.4 \pm 3.6$ & 0.98 \\
Compliance & 93.411 & 95.110 & 92.613 & 0.7 \\
Days of tea consumption (d) & 29.48 .0 & 33.223 & 31.810 & 0.6 \\
Medication $(\%):$ & & & & \\
$0-1$ & 39.4 & 23.5 & 24.0 & \\
$>1$ & 60.6 & 76.5 & 76.0 & 0.29 \\
\hline
\end{tabular}

Medication: Diabetes, hypertension, lipid/cholesterol lowering, antidepressant, benign prostate hypertrophy, anti-inflammatory, chronic obstructive pulmonary disease, erectile dysfunction. 
Table 2

Total phenolic and polyphenol content of six cups of GT and BT

\begin{tabular}{|c|c|c|}
\hline & Green Tea & Black Tea \\
\hline Total Phenolics (mg GAE) & $1215 \pm 17$ & $940 \pm 8.3$ \\
\hline EGCG (mg) & $571 \pm 41$ & $40 \pm 1.2$ \\
\hline EGC (mg) & $291 \pm 16$ & $8 \pm 0.7$ \\
\hline EC (mg) & $75 \pm 6.8$ & $12 \pm 0.3$ \\
\hline $\mathrm{ECG}(\mathrm{mg})$ & $89 \pm 6.6$ & $22 \pm 0.4$ \\
\hline Gallic acid (mg) & $17 \pm 3.3$ & $344 \pm 5.2$ \\
\hline THE (mg) & 0 & $35 \pm 3.6$ \\
\hline
\end{tabular}

a) Total phenolic content was expressed as gallic acid equivalent (GAE) (mean \pm std). 


\section{Table 3}

Serum phenolic acids in fasting serum from men consuming six cups of GT, BT or water collected at baseline and at the end of intervention on the morning of surgery

\begin{tabular}{llccc}
\hline & Time & Control $\mu \mathbf{m o l} / \mathbf{L}$ & \\
& & a & GT $\mu \mathbf{m o l} / \mathbf{L}$ & BT $\mu \mathbf{m o l} / \mathbf{L}$ \\
\hline 3,4DHPAA & Baseline & $101 \pm 112$ & $116 \pm 122$ & $90.0 \pm 138.9$ \\
& Post & $59 \pm 73$ & $135 \pm 160 b)$ & $\left.117 \pm 185^{b}\right)$ \\
3M4HPAA & Baseline & $170 \pm 174$ & $61 \pm 290$ & $154 \pm 187$ \\
& Post & $157 \pm 170$ & $199 \pm 192$ & $176 \pm 192$ \\
3HPAA & Baseline & $316 \pm 422$ & $302 \pm 305$ & $241 \pm 267$ \\
& Post & $316 \pm 434$ & $338 \pm 375$ & $261 \pm 290$ \\
4HPAA & Baseline & $568 \pm 458$ & $640 \pm 634$ & $541 \pm 465$ \\
& Post & $528 \pm 442$ & $798 \pm 895$ & $668 \pm 685$ \\
HA & Baseline & $1790 \pm 1720$ & $1910 \pm 1540$ & $1792 \pm 1814$ \\
& Post & $1730 \pm 2030$ & $1950 \pm 2040$ & $2305 \pm 1578$ \\
\hline
\end{tabular}

a) (mean \pm std; Cntr N=24, GT N=23 and BT N=22).

b) $\mathrm{BT}$ or GT compared to control for within subject change from baseline by group interaction $\mathrm{P}<0.05$ (repeated measures analysis of variance model was applied). 


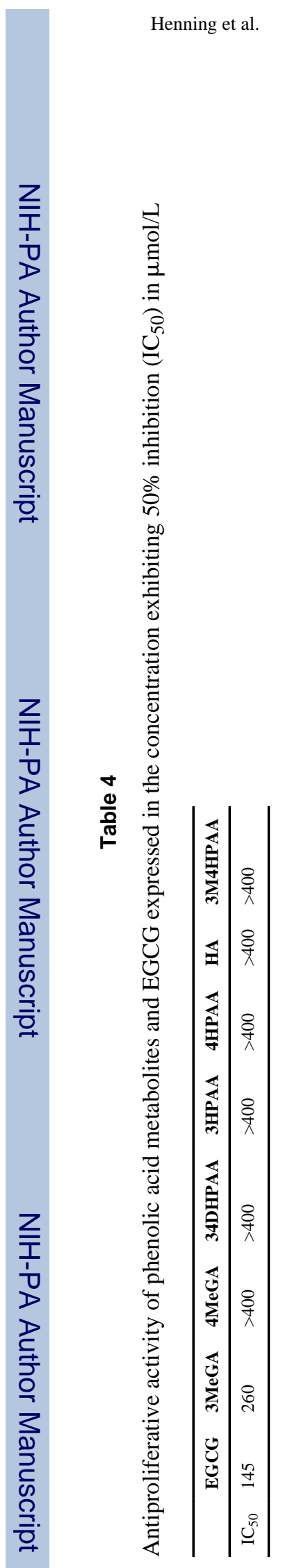

Mol Nutr Food Res. Author manuscript; available in PMC 2014 March 01. 